\title{
BMJ Open Risk assessment of workplace violence towards health workers in a Chinese hospital: a cross-sectional study
}

\author{
Yujie Liu, ${ }^{1}$ Min Zhang (D) , ${ }^{1}$ Rui Li, ${ }^{2}$ Na Chen, ${ }^{1}$ Yiming Huang, ${ }^{1}$ Yalan Lv, ${ }^{2}$ \\ Yuping Wang ${ }^{1}$
}

To cite: Liu Y, Zhang M, Li R, et al. Risk assessment of workplace violence towards health workers in a Chinese hospital: a crosssectional study. BMJ Open 2020;10:e042800. doi:10.1136/ bmjopen-2020-042800

- Prepublication history for this paper is available online. To view these files, please visit the journal online (http://dx.doi. org/10.1136/bmjopen-2020042800).

Received 15 July 2020 Revised 10 November 2020 Accepted 27 November 2020

Check for updates

(C) Author(s) (or their employer(s)) 2020. Re-use permitted under CC BY-NC. No commercial re-use. See rights and permissions. Published by BMJ.

${ }^{1}$ School of Population Medicine and Public Health, Chinese Academy of Medical Sciences and Peking Union Medical

College, Beijing, China

${ }^{2}$ The Third People's Hospital of Zhengzhou, Zhengzhou, China

Correspondence to

Dr Min Zhang;

zhangmin@sph.pumc.edu.cn

\section{ABSTRACT}

Objective This study aimed to assess the risk factors associated with workplace violence towards health workers (HWs) in a Chinese hospital.

Methods We conducted a cross-sectional survey in a Chinese secondary hospital in 2019 using an international survey questionnaire, and collected valid data from 1028 $\mathrm{HW}$ respondents via mobile phone. Alongside analysing the potential association between exposure to violence and respondents' characteristics, we compared the workplace violence between this survey and a baseline survey in the same hospital using the same questionnaire in 2018, and investigated the existing measures.

Results A total of $5.45 \%$ of respondents had encountered physical violence while $41.63 \%$ had experienced psychological violence. Women (OR=3.45, 95\% Cl 1.87 to 6.38), those working in outpatient and emergency departments $(\mathrm{OR}=7.96,95 \% \mathrm{Cl} 2.27$ to 27.95$)$, and those with extremely high concern about workplace violence $(\mathrm{OR}=7.94,95 \% \mathrm{Cl} 1.04$ to 60.85$)$ were significantly more likely to suffer physical violence. Working in the outpatient and emergency department $(\mathrm{OR}=2.03,95 \% \mathrm{Cl}$ 1.23 to 3.34$)$, having direct physical contact/interaction with patients $(\mathrm{OR}=2.98,95 \% \mathrm{Cl} 1.62$ to 5.49$)$, and extremely high worry about workplace violence $(\mathrm{OR}=6.47$ $95 \% \mathrm{Cl} 3.38$ to 12.40 ) significantly increased the risk of psychological violence. When the results of the baseline survey were compared with those in this survey, it was shown that physical violence declined significantly from $8.79 \%$ in 2018 to $5.45 \%$ in 2019 , while psychological violence declined significantly from $47.14 \%$ in 2018 to $41.63 \%$ in 2019 . The most recognised measures were security measures (81.03\%) while the least recognised measures were check-in procedures for staff (11.19\%). Conclusion Workplace violence towards HWs is a global problem with country-specific features. In our study, workplace violence in the hospital is of great concern. While demonstrating the effectiveness of measures in some degree, there is significant room for improvement. To achieve the vision of 'zero violence' in the health sector, aligned comprehensive measures should be systematically adopted.

\section{INTRODUCTION}

Workplace violence has become a global concern, with health workers (HWs) at major risk. ${ }^{1}$ However, ending workplace violence

\section{Strengths and limitations of this study}

This study is one of the limited studies in China to verify the effectiveness of measures against workplace violence at the hospital level using an international technical tool.

- An online version of the questionnaire was developed for WeChat, a popular Chinese social media app.

- Recall bias and selection bias should be considered when interpreting the results of this study.

- The study findings will support further policies to apply comprehensive measures in hospitals as well as international comparison.

- More empirical studies are required to examine the effectiveness of interventions against workplace violence for health workers in China.

requires international political commitment, and after many years of negotiations, in June 2019, the International Labour Office (ILO) adopted a convention (No. 190) and recommendation (No. 206) on violence in the world of work. The convention is a legally binding international instrument, while the recommendation provides advice and guidance on creating a better, safer and more decent working environment for women and men. ${ }^{2}$ The ILO report and tools did not emerge from a vacuum, however-previous studies by Richard Whittington, Nico Oud and others made a considerable contribution, particularly the definition and measurement tools for workplace violence in the health sector, anxiety, burnout and coping styles in general hospital staff exposed to workplace aggression, and the application of scales such as the Perceptions of Prevalence of Aggression Scale (POPAS), the Perception of Aggression Scale (POAS) and the Staff Observation Aggression Scale (SOAS).$^{3-6}$

In the last decade, China has witnessed an increase in workplace violence among HWs, while serious attacks and murders of HWs are not rare. In December 2019, an angry 
patient's son stabbed and killed a doctor at the emergency department of a Beijing hospital. ${ }^{7}$ In another incident in January 2020, an ophthalmologist was stabbed by a patient in a different Beijing hospital, and two other medical staff and another patient were injured. ${ }^{8}$ These vicious events of workplace violence in China have aroused public concern. ${ }^{9} 10$ Previous studies had shown that violence towards HWs has extremely negative impacts, such as HWs' impaired physical and mental health, decreased job satisfaction, increased mental stress and job burnout, and deterioration of the relationship between HWs and patients. ${ }^{11-14}$ Even worse, such incidents ultimately further impact the overall quality of medical and health services. ${ }^{1}$

There has been an abundance of literature on the prevalence, risk factors and mechanism of workplace violence towards HWs outside of China, particularly research conducted by international organisations and developed countries, such as studies on patterns and trends of workplace violence and its influencing factors, ${ }^{14-17}$ the complex causal factors of violence, and tailored approaches to prevent and eliminate workplace violence. ${ }^{18-20}$ Furthermore, technical tools on workplace violence prevention have been developed, particularly the Framework Guidelines for Addressing Workplace Violence in the Health Sector, ${ }^{1}$ its Training Manual ${ }^{11}$ and the Workplace Violence in the Health Sector Country Case Studies: Survey Questionnaire (hereafter referred to as the Questionnaire), which were jointly developed by the ILO, the International Council of Nurses (ICN), the WHO and the Public Services International (PSI).$^{22}$ There is also the Guidelines for Preventing Workplace Violence for Health Care and Social Service Workers, developed by the US Occupational Safety and Health Authority. ${ }^{23}$

In China, many articles have been published in recent years, with studies focussing on the prevalence of workplace violence among specific departments or specific subgroups of HWs. ${ }^{24-26}$ In some studies, suggestions of legislation for healthcare facilities based on international experience were formulated. ${ }^{27-29}$ In addition, systematic research has been conducted on the Chinese legal system relevant to workplace violence prevention and control. ${ }^{30}$ However, there are knowledge gaps in Chinese studies in terms of violence towards HWs, particularly in three aspects. (1) Few studies have used the full international recommended questionnaire (ie, the Questionnaire), while most surveys have been based on less reliable selfdesigned/self-modified questionnaires, or certain parts of the Questionnaire. ${ }^{31-33}$ (2) The definition and classification of violence in China varies across studies, which could lead to difficulty of comparison. ${ }^{27}$ (3) Most studies provide results from a single time cross-sectional survey, while few studies have followed up on the changes after implementing interventions to foster workplace violence prevention and control.

In this study, based on the definition of the ILO/ $\mathrm{PSI} / \mathrm{WHO} / \mathrm{ICN}$, we conducted a cross-sectional survey using an international technical tool at a central China secondary hospital in 2019, and compared the changes with the results of a baseline survey conducted at the same hospital in $2018,{ }^{34}$ to monitor the risk factors leading to workplace violence from the perspectives of existing measures. Based on the evidence from this study, we recommend comprehensive hospital-tailored approaches for further improvement.

\section{METHODS}

\section{Study population}

This study was conducted at a central China secondary general hospital (hereafter referred to as the Hospital), having received the permission of the Hospital manager to conduct the survey. The Hospital is located in the capital city of a province in central China, and has 1100 beds and more than 1600 staff.

The target population comprised all HWs (doctors, nurses, medical technical and administrative staff) in the Hospital. The inclusion criteria were: (1) HW with professional certification; (2) voluntarily participates in the survey with informed consent; (3) employed by the Hospital as a HW for more than 1 year.

\section{Questionnaire}

The original language of the Questionnaire used in our survey is English. ${ }^{22}$ The validity and reliability of translation into other language is critical; for instance, the Italian version of the Questionnaire was retested $(\alpha=0.61) .{ }^{35} \mathrm{We}$ formally obtained permission to use the Questionnaire from the ILO, before translating it into Chinese. Pretest and retest reliability and validity were conducted by our team in Beijing and Shenzhen city, with Cronbach's coefficient $\alpha$ at $0.83 .{ }^{34}$ The Questionnaire includes the following sections: (1) participants' demographic information (including department, professional title, education level, age, salary, gender, etc); (2) experience of physical violence and after-the-event interventions in the past 12 months; (3) experience of psychological violence (including verbal abuse, bullying/mobbing, racial harassment and sexual harassment) and after-the-event interventions in the past 12 months; (4) violence prevention measures in the hospital and opinion on the cause of violence by three open-ended questions.

\section{Data collection}

An online version of the questionnaire was developed for the Chinese popular social media forum WeChat. WeChat is the most used social media app in China, with more than 1 billion users. ${ }^{36}$ According to McKinsey, China has the world's most active environment for social media. There were more than 100 million mobile social users in 2010, a number that is forecast to grow by about $30 \%$ annually. The social-media market in China is vastly different from its counterpart in the west. ${ }^{37}$ When the survey was conducted, every health worker in the Hospital was a WeChat user, with specific WeChat groups used for different tasks, such as by department or theme task force. Therefore, this was an effective mode 
Table 1 Proportion of valid respondents and included health workers by gender and occupation

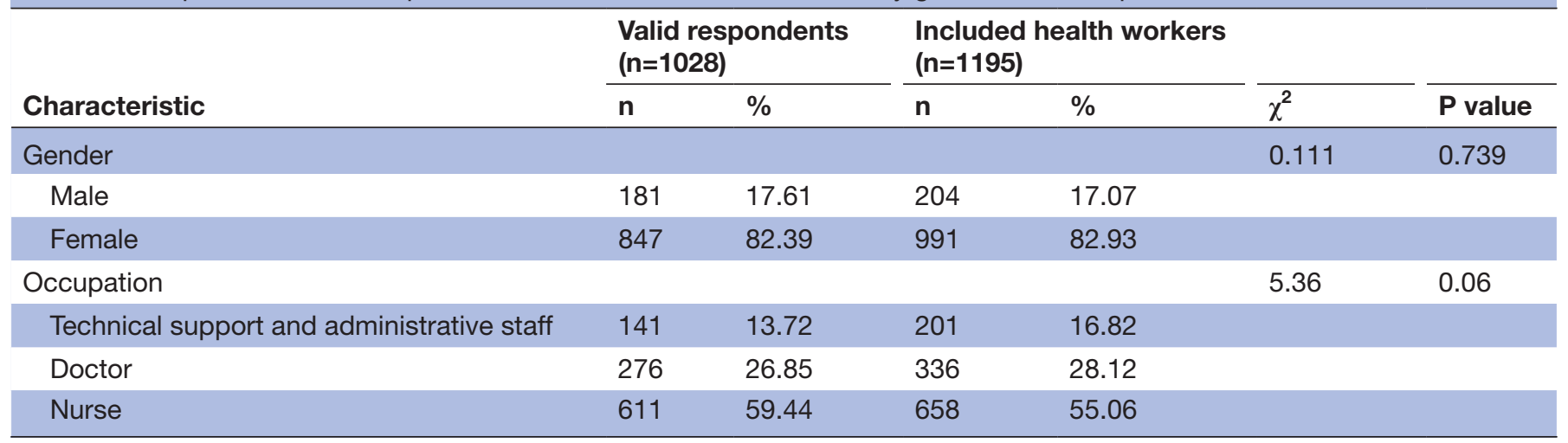

of communication. HWs could access the survey by scanning the particular quick response code with their smartphone or tablet.

The front page of the questionnaire comprised a statement of consent, including anonymity, confidentiality and voluntary participation. The Chinese version of the survey questionnaire can be found in online (https:// www.wjx.cn/jq/42686466.aspx).

In July 2019, under the coordination of the managerial department of the Hospital, our team member went to the relevant departments, and invited HWs on duty to fill in the questionnaire using their own mobile phones during a period of 7 days. The number of HWs who met the inclusion criteria was 1195 . The data management platform showed that 1032 respondents who met the inclusion criteria completed the questionnaire, of whom 1028 had valid questionnaires (total response rate $86.36 \%$; total valid response rate $86.02 \%$ ). There was no significant difference between the proportion of valid respondents and included HWs who met the inclusion criteria in the Hospital by gender and occupation (table 1).

As mentioned earlier, in June 2018, a cross-sectional survey had been conducted with the same questionnaire by our team at the same Hospital. ${ }^{34}$ In this article, this is defined as the baseline survey. Comparison of the frequency of workplace violence was conducted between this survey and the baseline survey.

\section{Quality control}

All members of our investigation team were trained with respect to the background of the investigation and the concepts of workplace violence.

Before the field survey, Hospital leaders organised a meeting for the head nurses and directors of relevant departments. The team explained the purpose and importance of the survey and called for support and participation from the HWs.

After collecting the questionnaire from the online management platform, the questionnaire data were verified by two team members, and logical errors were deleted or corrected when both members agreed. The database was then coded for further analysis.

\section{Statistical analysis}

The data were analysed using IBM SPSS Statistics V.22.0 and Excel. First, descriptive statistics were calculated for demographic and frequency of physical and psychological violence.

Second, a $\chi^{2}$ test was used for univariate analysis to test the potential association between exposure to physical violence, psychological violence in general (yes/no), and respondents' characteristics. Significant factors were modelled in binary logistic regression analysis to calculate ORs with CIs by using the forward stepwise (likelihood ratio) method, which showed the association between these factors and workplace violence. Statistical significance was defined as $\mathrm{p}<0.05$.

Third, the features of occurrence and response of physical violence among participants who had experienced physical violence were analysed.

Fourth, a comparison was conducted of frequency changes to workplace violence between this survey and the baseline survey.

Fifth, recognition of existing measures against violence was evaluated.

\section{Patient and public involvement}

No patients were involved in the design, recruitment or conduct of the study. The Hospital under survey was offered a summary of the study results.

\section{RESULTS}

\section{Incidence and distribution of workplace violence}

Of the 1028 respondents who completed valid questionnaires, most were women $(82.39 \%)$ and nurses $(59.44 \%)$. A total of $56(5.45 \%)$ respondents had encountered physical violence while $428(41.63 \%)$ had experienced psychological violence in the past 12 months. Verbal abuse (413, $40.18 \%$ ) was the most common form of psychological violence, followed by bullying/mobbing (102, 9.92\%). In addition, the number of respondents who had experienced racial discrimination and sexual harassment were $16(1.56 \%)$ and $20(1.95 \%)$, respectively. The descriptive association between respondents' characteristics and 
Table 2 Characteristics and frequency distributions for violence among $1028 \mathrm{HWs}$

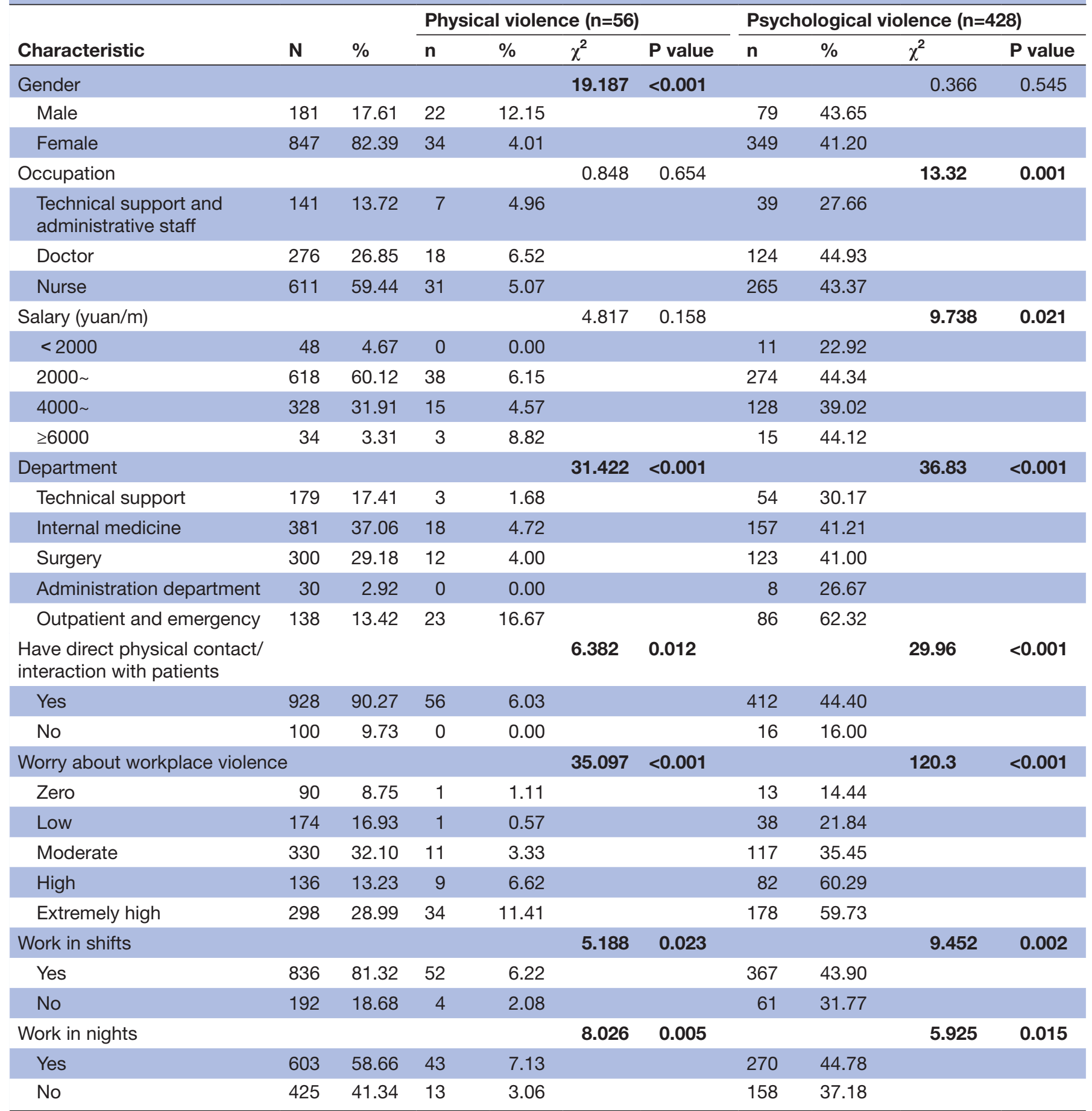

Bold values are statistics significant at $\mathrm{p}<0.05$.

exposure to psychological/physical violence in the past 12 months is shown in table 2 .

\section{Binary logistic regression}

Table 3 shows the results of binary logistic regression. It indicates that gender, department and level of worry about workplace violence are related to the occurrence of workplace violence. Female respondents had a greater risk of physical violence than male respondents $(\mathrm{OR}=3.45$,
95\% CI 1.87 to 6.38). Respondents in outpatient and emergency departments were 7.96 times (95\% CI 2.27 to 27.95) more exposed to physical violence. Those with extremely high concern about workplace violence were 7.94 times (95\% CI 1.04 to 60.85) more likely to suffer from physical violence. Working in outpatient and emergency departments $(\mathrm{OR}=2.03,95 \%$ CI 1.23 to 3.34$)$ and having direct physical contact/interaction with patients 
Table 3 Binary logistic regression of physical $(n=56)$ and psychological violence $(n=428)$

\begin{tabular}{|c|c|c|}
\hline & OR & $95 \% \mathbf{C l}$ \\
\hline \multicolumn{3}{|l|}{ Physical violence } \\
\hline \multicolumn{3}{|l|}{ Gender } \\
\hline Male & 1.00 & Reference \\
\hline Female† & 3.45 & 1.87 to 6.38 \\
\hline \multicolumn{3}{|l|}{ Department } \\
\hline $\begin{array}{l}\text { Technical support and } \\
\text { administration }\end{array}$ & 1.00 & Reference \\
\hline Internal medicine & 3.30 & 0.93 to 11.64 \\
\hline Surgery & 2.18 & 0.60 to 8.00 \\
\hline Outpatient and emergency† & 7.96 & 2.27 to 27.95 \\
\hline \multicolumn{3}{|l|}{ Worry about workplace violence } \\
\hline Zero & 1.00 & Reference \\
\hline Low & 0.52 & 0.03 to 8.63 \\
\hline Moderate & 2.47 & 0.31 to 19.86 \\
\hline High & 5.06 & 0.61 to 41.87 \\
\hline Extremely high* & 7.94 & 1.04 to 60.85 \\
\hline \multicolumn{3}{|l|}{ Psychological violence } \\
\hline \multicolumn{3}{|l|}{ Department } \\
\hline $\begin{array}{l}\text { Technical support and } \\
\text { administration }\end{array}$ & 1.00 & Reference \\
\hline Internal medicine & 1.00 & 0.66 to 1.50 \\
\hline Surgery & 1.07 & 0.70 to 1.63 \\
\hline Outpatient and emergency $†$ & 2.03 & 1.23 to 3.34 \\
\hline \multicolumn{3}{|c|}{ Have direct physical contact/interaction with patients } \\
\hline Yes & 1.00 & Reference \\
\hline Not & 2.98 & 1.62 to 5.49 \\
\hline \multicolumn{3}{|l|}{ Worry about workplace violence } \\
\hline Zero & 1.00 & Reference \\
\hline Low & 1.41 & 0.70 to 2.84 \\
\hline Moderate† & 2.63 & 1.38 to 5.02 \\
\hline Hight & 7.11 & 3.54 to 14.28 \\
\hline Extremely high† & 6.47 & 3.38 to 12.40 \\
\hline
\end{tabular}

*Significant at $p<0.05$.

†Significant at $p<0.01$.

$(\mathrm{OR}=2.98,95 \%$ CI 1.62 to 5.49) increased the risk of experiencing psychological violence. Respondents with a higher level of worry about workplace violence suffered significantly more psychological violence from moderate $(\mathrm{OR}=2.63,95 \% \mathrm{CI} 1.38$ to 5.02$)$ to extremely high $(\mathrm{OR}=6.4795 \%$ CI 3.38 to 12.40$)$.

Features of occurrence of and response to physical violence Among the 56 respondents who had experienced physical violence, most of the perpetrators were patients' relatives $(71.43 \%)$ or the patients themselves $(58.93 \%)$. Most of the physical violence occurred in the hospital (83.93\%).
Table 4 The occurrence of and response to physical violence $(n=56)$

\begin{tabular}{|c|c|c|}
\hline Item & Frequency & $\%$ \\
\hline \multicolumn{3}{|l|}{ Perpetrators (multiple-choice) } \\
\hline Relatives of patient & 40 & 71.43 \\
\hline Patients & 33 & 58.93 \\
\hline Coworkers & 4 & 7.14 \\
\hline Visitors & 3 & 5.36 \\
\hline Administrators & 2 & 3.57 \\
\hline Other & 1 & $1.7 \mathrm{c}$ \\
\hline \multicolumn{3}{|l|}{ Location } \\
\hline Hospital & 47 & 83.93 \\
\hline Patients' home & 3 & 5.36 \\
\hline $\begin{array}{l}\text { Outside (on way to work/ } \\
\text { health visit/home) }\end{array}$ & 6 & 10.71 \\
\hline \multicolumn{3}{|l|}{ Violence-caused injuries } \\
\hline $\begin{array}{l}\text { Yes } \\
\text { No }\end{array}$ & 21 & 37.50 \\
\hline No & 35 & 62.50 \\
\hline \multicolumn{3}{|c|}{ Action taken to investigate the violence } \\
\hline Yes & 18 & 32.14 \\
\hline No & 38 & 67.86 \\
\hline
\end{tabular}

Twenty-one $(37.50 \%)$ respondents were injured as a result of the violent incidents, but only $33.30 \%$ required formal treatment, and only $5.36 \%$ took time off work after being attacked. Of 18 respondents who encountered the physical violence had been taken action of investigation, only $33.33 \%$ called the police, while $55.56 \%$ of the incidents were official managed (including verbal warning, stopped health services, notifying the police) (table 4).

\section{Changes in frequency of workplace violence between this survey and the baseline survey}

As shown in table 5, when the results of this survey were compared with those in the baseline survey, physical violence declined significantly from $8.79 \%$ in 2018 to $5.45 \%$ in 2019 , while psychological violence declined significantly from $47.14 \%$ in 2018 to $41.63 \%$ in 2019 . Furthermore, for psychological violence, verbal abuse fell significantly from $45.71 \%$ in 2018 to $40.18 \%$ in 2019 , while bullying/mobbing dropped significantly from $12.78 \%$ in 2018 to $9.92 \%$ in 2019 .

We compared the characteristics of respondents between the baseline survey and this survey, but found no significant difference among most features (gender, occupation, salary, having direct physical contact/interaction with patients, worry about workplace violence, working in shifts and working nights).

\section{Existing measures against workplace violence}

After the baseline survey, the Hospital intervened in workplace violence using multiple countermeasures. In general, the Hospital has established an organisational 
Table 5 Comparison of the incidence rate between the two waves of survey

\begin{tabular}{|c|c|c|}
\hline & $\begin{array}{l}\text { Baseline } \\
\text { survey }(n=978)\end{array}$ & $\begin{array}{l}\text { This } \\
\text { survey } \\
(n=1028)\end{array}$ \\
\hline \multicolumn{3}{|l|}{ Physical violence $†$} \\
\hline Number & 86 & 56 \\
\hline Incidence rate (\%) & 8.79 & 5.45 \\
\hline \multicolumn{3}{|c|}{ Psychological violence* } \\
\hline Number & 461 & 428 \\
\hline Incidence rate (\%) & 47.14 & 41.63 \\
\hline \multicolumn{3}{|l|}{ Verbal abuse* } \\
\hline Number & 447 & 413 \\
\hline Incidence rate (\%) & 45.71 & 40.18 \\
\hline \multicolumn{3}{|l|}{ Bullying/Mobbing* } \\
\hline Number & 125 & 102 \\
\hline Incidence rate (\%) & 12.78 & 9.92 \\
\hline \multicolumn{3}{|l|}{ Sexual harassment } \\
\hline Number & 23 & 20 \\
\hline Incidence rate (\%) & 2.35 & 1.95 \\
\hline \multicolumn{3}{|l|}{ Racial harassment } \\
\hline Number & 21 & 16 \\
\hline Incidence rate (\%) & 2.15 & 1.56 \\
\hline
\end{tabular}

*Significant at $p<0.05$.

†Significant at $p<0.01$

structure against workplace violence, led by the chairman of the labour union and the director of the nursing management department. The head nurses and directors of each department are the backbone of efforts to counteract workplace violence. The measures were technically guided by the occupational health team from the School of Public Health of Peking Union Medical College.
Under the organisational structure, figure 1 shows the valuation of the existing 12 measures against workplace violence that were listed on the Questionnaire by respondents: security measures (eg, guards, alarms, portable telephones) was the most recognised measure $(81.03 \%)$, followed by improved surroundings (eg, lighting, noise, heat, access to food, cleanliness, privacy) in second place (52.33\%), while the proportion of other measures ranged between $20 \%$ and $30 \%$, and the least recognised measure was check-in procedures for staff (especially for home care) $(11.19 \%)$.

In detail, the specific measures included: setting up police stations and 24 hours security patrols in the hospital, participating in the national Healthwise training course, providing training for HWs by national experts, and creating social media groups (WeChat group) among HWs on workplace violence prevention and control.

\section{DISCUSSION \\ Comparison of the incidence rate with international study}

We compared our findings with the international jointstudy launched by the ILO, ICN, WHO and PSI among Australia, Thailand, Bulgaria, Brazil and others during 2000-2002, which adopted the same definition of physical and psychological violence as our study. The percentage of HWs who suffered physical violence $(5.45 \%)$ in our survey was lower than that in Australia (12.0\%), Thailand $(10.5 \%)$, Bulgaria $(7.5 \%)$ and Brazil $(6.4 \%) .{ }^{38}$ From the perspective of psychological violence, the top three incidence rates in our survey were verbal abuse $(40.18 \%)$, bullying/mobbing $(9.92 \%)$ and racial and sexual harassment $(3.51 \%)$. The order was similar to the international study, but the incidence rates of verbal abuse in our study were higher than those in Brazil $(39.5 \%)$ and Bulgaria $(32.2 \%)$, and lower than in Thailand $(47.7 \%)$ and Australia $(67.0 \%) .{ }^{38}$ However, the direct comparison between nations needs to be considered carefully,

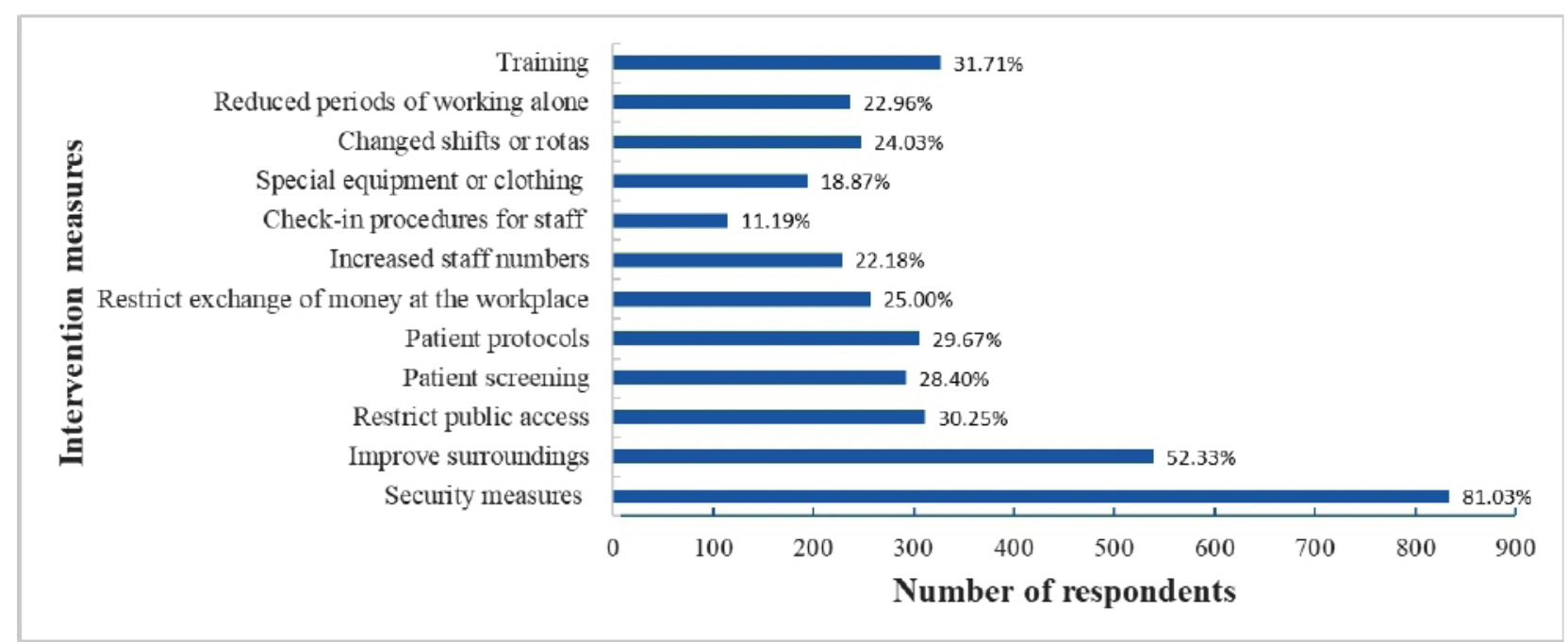

Figure 1 Evaluation of existing measures against workplace violence among respondents. 
particularly around the internal validity and reliability of each translation. Although the incidence of workplace violence in this survey is lower than that in some countries, it cannot be simply concluded that the situation of workplace violence in China is more or less severe than that in foreign countries, due to the different years of investigation, and the diverse institutional, social, economic and cultural context in health facilities; hence, the data showed that workplace violence is a global problem with country-specific features.

Other than the Questionnaire, other measurement instruments of workplace violence in the health sector could be used for further study, such as POPAS, POAS, SOAS and the Impact of Events Scale (IES), particularly among psychiatric HWs. ${ }^{3}$

\section{Risk factors and changes between the two waves of survey}

Similar to the baseline survey, ${ }^{34}$ the workplace violence in this survey was perpetrated mainly by patients $(58.93 \%)$ and their families $(71.43 \%)$, with our findings also confirming the results of other studies. ${ }^{33} 39$ According to the analysis from the literature, the main causes of workplace violence may be the information asymmetry between doctors and patients/their families. Most patients and their families have insufficient medical knowledge, and they expect too much from the treatment so that dissatisfaction may lead to violence. ${ }^{39-41}$ However, we could not fully agree with that, and our analysis of risk factors in the next paragraph provides new views.

This survey indicated that some perpetrators of workplace violence were colleagues $(7.14 \%)$ and administrators $(3.57 \%)$ in the Hospital. As similarly reported by a study in Chinese township hospitals, in a small number of cases, colleagues $(0.64 \%-5.09 \%)$ and superiors $(1.28 \%-4.52 \%)$ were the perpetrators of violence towards general practitioners and general nurses. ${ }^{32}$ While workplace violence between HWs has mostly been ignored by studies in China, it is worth noticing the potential negative impact of violence between coworkers. In contrast, the National Health Service Staff Survey is a large workforce survey in the UK that has been conducted every year since 2003. It has continually focused on the index of bullying and harassment between staff, with the results of 2019 showing that $12.3 \%$ and $19.0 \%$ of staff experienced at least one incident of bullying, harassment or abuse in the last 12 months from managers and other colleagues, respectively. ${ }^{42}$

In this survey, HWs in outpatient and emergency departments had a higher risk of both physical and psychological violence, which is similar to both our baseline survey and the meta-analysis of other Chinese studies. ${ }^{31,34}$ In general, the tiered healthcare delivery system is underdeveloped in China, the number of patients in outpatient and emergency departments is staggering, and patients and their relatives in outpatient and emergency departments are more anxious and sensitive than those in inpatient departments, thus increasing the possibility of conflicts and workplace violence.
This survey found that HWs with a higher level of worry about workplace violence were more likely to suffer both physical violence (7.96 times) and psychological violence (2.03 times) than those who were not, which verified the phenomenon in previous studies. ${ }^{24}{ }^{43}$ The worry of HWs means that they do not trust that hospital measures will effectively protect them from violence. HWs under a constant state of worry inevitably adopt avoidance behaviours and a negative work attitude, which may lead to aggravated dissatisfaction of patients and their families, thus increasing the risk of violence. This is consistent with the cyclical model reported by Whittington and Wykes, which suggests that stress induced by exposure to violence leads to impaired staff performance and adoption of behaviours, which make the re-occurrence of violence more likely. ${ }^{44}$ Based on the findings from New Zealand that anxiety is a risk factor, an intervention was developed and the findings showed that communication skills training improved staff confidence in dealing with aggression. ${ }^{45}$

Regarding the effect of the listed 12 measures, after the baseline survey, there was a significant decrease in physical violence, psychological violence in general, as well as verbal abuse and bullying/mobbing, even though most of the measures have not been fully implemented. This demonstrated that the measures were effective to some degree, but there is significant room for improvement. For instance, management of the emergency response to workplace violence is not well-developed in the Hospital; only a very low percentage of victims required formal treatment and they would rather 'keep silence' than immediately stop their ongoing health service.

\section{Suggestions for policy making at the hospital level}

From the requirements of the ILO convention (No. 190) and recommendation (No. 206), the government shall adopt laws and regulations requiring employers to take appropriate steps to prevent violence and harassment in the world of work. ${ }^{2}$

In China, the Law on Basic Health Care and Health Promotion was adopted on 28 December 2019, and took effect on 1 June 2020. This is the first fundamental law in the health sector in China. It clearly stipulates that those who disrupt the order of medical institutions, threaten or endanger the personal safety of medical personnel, violate the personal dignity of medical personnel or act against the administration of public security shall face punishment according to law. ${ }^{76}$ In addition, there are 10 laws and 2 administrative regulations relevant to the safety and health of HWs from the legal authority of mental health, infectious diseases, occupational diseases and others. ${ }^{30}$

In accordance with the current laws and regulations, it is the legal responsibility of employers to provide a safe and decent working environment for employees, with protection of the legitimate rights and interests of HWs, and in particular to protect HWs by providing a workplace that is free from violence. However, there 
is currently no national guideline in China that plays this role, with hospital measures mainly focused on responding to extreme violence events (criminal cases). ${ }^{46}$ Our study confirmed that among the 12 measures, security measures were the highest percentage to be currently implemented, but these measures were reactive rather than proactive, and tackled a particular risk (physical violence) rather than workplace violence as a whole.

In light of the international and national experiences, it is only with comprehensive measures that we can reinforce aligned actions against workplace violence at hospitals, due to the complex causes and risk factors of workplace violence. The 12 measures provided by the Questionnaire were widely recognised comprehensive measures to address the risk factors of workplace violence; therefore, we suggest the key issues in comprehensive measures at the hospital level in China: (1) to create a positive culture for the vision of 'zero violence'. The values of respect, tolerance, gender-sensitivity, equality, cooperation and care for safety and health of HWs are essential; a harmonious doctor-patient relationship should be built; and no form of workplace violence should be tolerated. (2) To conduct organisational interventions, the hospitals ought to invest in human resource development. Improving staff shortages will reduce work pressure between HWs and patients, the number and skills of HWs are critical to cope with workplace violence, and good work organisation can minimise the number of consecutive nightshifts and working for long hours. (3) To implement environmental interventions, hospitals need to optimise the service delivery procedure to reduce the waiting time, to design a comfortable and convenient waiting area, to set the alarm system at appropriate locations, and design escape doors in high-risk departments (such as emergency). It is crucial to restrict public access, including conducting security checks on visitors, and providing safety areas for staff (such as dressing rooms). (4) To adopt after-the-event interventions, hospitals are required to provide victims with medical treatment, psychological counselling and compensation measures, while perpetrators should be punished in accordance with the laws. (5) To develop measurement tools for evidence-based prevention and control, it is urgent for health authorities to introduce and modify useful tools from other countries, such as measurement for the occurrence rate of violence (POPAS, POAS, SOAS), the impact of violence (IES) and risk assessment (the Emergency Department Workplace Violence Questionnaire). (6) To establish an active reporting and notification system, the health authorities need to employ routine provider reporting mechanisms to increase provider reporting, improve the data on patient violence and consequentially work towards combatting this public affairs problem. ${ }^{129}$ 47-49

\section{Limitations and strengths}

There are some limitations to be considered when interpreting the results of this study. First, this survey is a cross-sectional study, and it cannot analyse the causal relationship between variables. Second, respondents' recall of workplace violence events that occurred in the past 12 months may lead to recall bias. Psychological violence is more obscure than physical violence, but it is more likely to be under reported. Third, the severity of psychological violence could not be further analysed due to the complexity and limited space. Finally, we conducted the survey through the popular social media app WeChat, making it possible that those with low skill levels in smartphone or tablet use avoided participating in or completing our survey. This led to selection bias for participants, while the social media survey may be difficult to implement in other countries due to cultural differences. However, the adoption of international definitions and a questionnaire on workplace violence in this survey enhances the validation of international comparison, and our results support policies for further intervention with comprehensive measures in Chinese hospitals, including continual efforts in the Hospital as well as the extension of such efforts to hospitals countrywide. To our knowledge, our study is one of a limited number of studies in China to verify the effectiveness of measures against workplace violence at the hospital level using the international technical tool.

\section{CONCLUSION}

Workplace violence towards HWs is a global problem with country-specific features. In our study, workplace violence in the Hospital is of great concern. In terms of the 12 measures implemented after the baseline survey, there was a significant decrease in physical violence, psychological violence in general, as well as verbal abuse and bullying/mobbing. This demonstrated that the measures are effective in some degree, but there is significant room for improvement. To achieve the vision of 'zero violence' in the health sector, aligned comprehensive measures should be systematically adopted, including creating a positive culture, conducting organisational interventions, implementing environmental interventions, adopting after-the-event interventions, developing risk assessment and evaluation procedures, and establishing an active reporting and notification system. Meanwhile, more empirical studies are required to focus on the effectiveness of intervention against workplace violence for HWs in China.

Acknowledgements The authors acknowledge Dr Yingdong Zheng (Peking University) for his technical guidance during the data analysis of the study. We also appreciate the support of from Shuya Zhao (master degree candidate) and Hui Qu (master degree candidate) in the Hospital. Meanwhile, the authors would like to thank the other staff who involve in the study at the Hospital for their contribution.

Contributors MZ was the principal investigator of the study, responsible for and main contributor to all phases of the study: the study design, quality assessment and the manuscript modifying. NC, YLiu, YH, RL and YLv collected the data. YLiu, YH and YW analysed the data. YLiu drafted the manuscript. All authors approved the final manuscript for publication.

Funding The publishing was funded by the Chinese Academy of Medical Sciences/ Peking Union Medical College, China (number of programme: School of Public Health 03010702). 
Competing interests None declared.

Patient and public involvement Patients and/or the public were not involved in the design, or conduct, or reporting, or dissemination plans of this research.

\section{Patient consent for publication Not required.}

Ethics approval This study was automatically approved by the Ethical Review Committee of the Chinese Academy of Medical Sciences according to internal regulations (number of approval: School of Public Health 03010702). All personal identifiers (name, contact) were removed from the data set for analyses.

Provenance and peer review Not commissioned; externally peer reviewed.

Data availability statement All data relevant to the study are included in the article or uploaded as supplementary information. Data are available upon reasonable request. All data relevant to the study are included in the article or uploaded as supplementary information. The data supporting the conclusion of this article are included in the article. No additional data available. The data sets used and analysed during the current study are available from the corresponding author on reasonable request.

Open access This is an open access article distributed in accordance with the Creative Commons Attribution Non Commercial (CC BY-NC 4.0) license, which permits others to distribute, remix, adapt, build upon this work non-commercially, and license their derivative works on different terms, provided the original work is properly cited, appropriate credit is given, any changes made indicated, and the use is non-commercial. See: http://creativecommons.org/licenses/by-nc/4.0/.

\section{ORCID iD}

Min Zhang http://orcid.org/0000-0003-4273-6836

\section{REFERENCES}

1 International Labour Office (ILO). The International Council of nurses (ICN), the world Health organization (who) and the public services International (PSI). framework guidelines for addressing workplace violence in the health sector, 2002. Available: http://www.who. int/violence_injury_prevention/violence/activities/workplace/en/ [Accessed 18 Jul 2020]

2 ILO. New international labour standard to combat violence, harassment, at work agreed. Available: https://www.ilo.org/ilc/ ILCSessions/108/media centre/news/WCMS_711321/lang-en/index. htm [Accessed 18 Jul 2020].

3 Nijman H, Bowers L, Oud N, et al. Psychiatric nurses' experiences with inpatient aggression. Aggress Behav 2005;31:217-27.

4 Winstanley S, Whittington R. Anxiety, burnout and coping styles in general Hospital staff exposed to workplace aggression: a cyclical model of burnout and vulnerability to aggression. Work \& Stress 2002;16:302-15.

5 Wykes T, Whittington R. Prevalence and predictors of early traumatic stress reactions in assaulted psychiatric nurses. J Forensic Psychiatry 1998;9:643-58.

6 Palmstierna T, Barredal E. R.N. evaluation of the perception of aggression scale (POAS) Swedish nurses, 2009: 447-51.

7 Lancet. Protecting Chinese doctors. Lancet 2020;395:90.

8 Global Times. Medical staff, resident attacked at Beijing hospital weeks since doctor's murder. Available: http://www.globaltimes.cn/ content/1177423.shtml [Accessed 18 Jul 2020].

9 Hesketh T, Wu D, Mao L, et al. Violence against doctors in China. BMJ 2012;345:e5730

10 Pan Y, Yang Xhong, He JP, et al. To be or not to be a doctor, that is the question: a review of serious incidents of violence against doctors in China from 2003-2013. J Public Health 2015;23:111-6.

11 Tang N, Thomson LE. Workplace violence in Chinese hospitals: the effects of healthcare disturbance on the psychological well-being of Chinese healthcare workers. Int J Environ Res Public Health 2019;16:3687.

12 Zhan Y, Kim SK, Zhou L, et al. Patient violence and health professionals' occupational outcomes in China: a time-lagged survey study. Int J Nurs Stud 2019;94:120-30.

13 Roche M, Diers D, Duffield C, et al. Violence toward nurses, the work environment, and patient outcomes. J Nurs Scholarsh 2010;42:13-22.

14 Akbolat M, Sezer C, Ünal Özgün, et al. The effects of direct violence and witnessed violence on the future fear of violence and turnover intention: a study of health employees. Curr Psychol $2019 ; 27$.
15 Schnapp BH, Slovis BH, Shah AD, et al. Workplace violence and harassment against emergency medicine residents. West $J$ Emerg Med 2016;17:567-73.

$16 \mathrm{Al}-O m a r i \mathrm{H}$. Physical and verbal workplace violence against nurses in Jordan. Int Nurs Rev 2015;62:111-8.

17 Sisawo EJ, Ouédraogo SYYA, Huang S-L. Workplace violence against nurses in the Gambia: mixed methods design. BMC Health Serv Res 2017;17:311.

18 Berlanda S, Pedrazza M, Fraizzoli M, et al. Addressing risks of violence against healthcare staff in emergency departments: the effects of job satisfaction and attachment style. Biomed Res Int 2019;2019:1-12.

19 Oh H, Uhm DC, Yoon YJ. Factors affecting workplace bullying and lateral violence among clinical nurses in Korea: descriptive study. $J$ Nurs Manag 2016;24:327-35.

20 Wassell JT. Workplace violence intervention effectiveness: a systematic literature review. Saf Sci 2009;47:1049-55.

21 ILO, PSI, WHO, ICN. Framework guidelines for addressing workplace violence in the health sector: the training manual. Available: http:// www.ilo.org/safework/info/instr/WCMS_108542/lang-en/index.htm [Accessed $18 \mathrm{Jul}$ 2020].

22 ILO, PSI, WHO, ICN. Workplace violence in the health sector country case studies research instruments: survey questionnaire. Geneve: ILO, 2003. Available: https://www.who.int/violence_injury_prevention/ violence/interpersonal/en/WVquestionnaire.pdf?ua=1 [Accessed 26 Oct 2020].

23 Occupational Safety and Health Administration (OSHA). Guidelines for preventing workplace violence for health care social service workers. Washington DC: OSHA, 2004.

24 Jiao M, Ning N, Li Y, et al. Workplace violence against nurses in Chinese hospitals: a cross-sectional survey. BMJ Open 2015;5:e6719.

25 Yao Y, Wang W, Wang F, et al. General self-efficacy and the effect of hospital workplace violence on doctors' stress and job satisfaction in China. Int J Occup Med Environ Health 2014;27:389-99.

26 Han C-Y, Lin C-C, Barnard A, et al. Workplace violence against emergency nurses in Taiwan: a phenomenographic study. Nurs Outlook 2017;65:428-35.

27 Zhang M. International consensus on workplace violence in health sector and its meaning to practice in China. Chinese Nursing Management 2019;19:923-8.

$28 \mathrm{LH} \mathrm{X.} \mathrm{Development} \mathrm{of} \mathrm{international} \mathrm{labour} \mathrm{standard} \mathrm{relevant} \mathrm{to}$ violence and harassment in the world of work. Chinese Nursing Management 2019;19:487-93.

29 Zhang M. How to implement workplace violence prevention and control at hospital level? Chinese Nursing Management 2019:19:481-7.

30 Liu T, Zhang M, LH X, et al. Chinese laws and regulations on workplace violence in healthcare settings: systematic analysis and policy recommendations. Chinese Occupational Medicine 2017;44:290-6.

31 Lu L, Dong M, Wang S-B, et al. Prevalence of workplace violence against health-care professionals in China: a comprehensive meta-analysis of observational surveys. Trauma Violence Abuse 2020;21:498-509.

32 Li P, Xing K, Qiao H, et al. Psychological violence against general practitioners and nurses in Chinese township hospitals: incidence and implications. Health Qual Life Outcomes 2018;16:117.

33 Xing K, Jiao M, Ma H, et al. Physical violence against general practitioners and nurses in Chinese township hospitals: a crosssectional survey. PLoS One 2015;10:e142954.

34 Chen N, Zhang M, Li R, et al. Investigation on workplace violence in a grade $2 \mathrm{~A}$ hospital-A survey using the investing tool for workplace violence in hospitals developed by the world Health organization. Chinese Occupational Medicine 2019;46:157-62 http://gb.oversea. cnki.net/KCMS/detail/detail.aspx?filename=XYYX201902005\& dbcode $=$ CJFD\&dbname $=$ DKFXTEMP

35 La Torre G, Sestili C, lavazzo E, et al. [Workplace Violence in the health sector: validation of the Italian version of the WHO questionnaire]. Clin Ter 2017;168:e199-202.

36 Fashion China. What is the most used social media in China? Available: http://fashionchinaagency.com/social-media-agencyshanghai-china/ [Accessed 28 Oct 2020].

37 Chiu C, Ip C, Silverman A. Understanding social media in China. McKinsey Quarterly. Available: https://www.mckinsey.com/businessfunctions/marketing-and-sales/our-insights/understanding-socialmedia-in-china [Accessed 28 Oct 2020].

38 MARTINO VD. Workplace violence in the health sector country: case studies. Geneve: International Labor Office, 2003. 
39 Yang SZ, Wu D, Wang N, et al. Workplace violence and its aftermath in China's health sector: implications from a cross-sectional survey across three tiers of the health system. BMJ Open 2019;9:e31513.

40 Violence against doctors: why China? why now? what next? Lancet 2014;383:1013.

41 Li Z, Yan C, Shi L, et al. Workplace violence against medical staff of Chinese children's hospitals: A cross-sectional study. Plos One 2017; 12:e179373.

42 NHS England. Nhs staff survey 2019 national results briefing. Available: https://www.nhsstaffsurveys.com/Page/1056/Home/NHSStaff-Survey-2019/ [Accessed 18 Jul 2020].

43 Sun P, Zhang X, Sun Y, et al. Workplace violence against health care workers in North Chinese hospitals: a cross-sectional survey. Int $J$ Environ Res Public Health 2017;14:96.

44 Whittington R, Wykes T. An observational study of associations between nurse behaviour and violence in psychiatric hospitals. $J$ Psychiatr Ment Health Nurs 1994;1:85-92.
45 Baby M, Gale C, Swain N. A communication skills intervention to minimise patient perpetrated aggression for healthcare support workers in New Zealand: a cluster randomised controlled trial. Health Soc Care Community 2019;27:170-81.

46 Huang J, Zhang M, Liu X. Correlation between patient and visitor violence and workload among public healthcare workers in China: a cross-sectional study. BMJ Open 2020;10:e34605.

47 Merchant JA, Lundell JA. Workplace violence intervention research workshop, April 5-7, 2000, Washington, DC. background, rationale, and summary. Am J Prev Med 2001;20:135-40.

48 G.d'Ettorre A, Caroli V, Pellicani GC. Preliminary risk assessment of workplace violance in hospital emergency departments. Ann Lg 2020;32:99-108.

49 Campbell CL, Burg MA, Gammonley D. Measures for incident reporting of patient violence and aggression towards healthcare providers: a systematic review. Aggress Violent Behav 2015;25:314-22. 